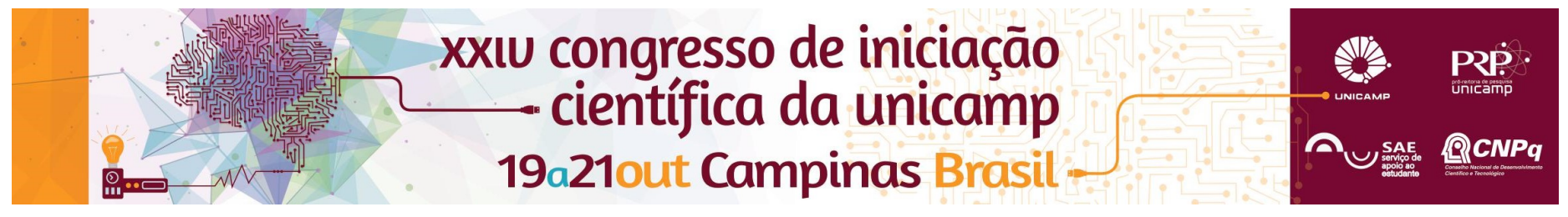

\title{
EFEITOS DA RADIOTERAPIA SOBRE A MICRODUREZA, COMPOSIÇÃO MINERAL E MORFOLOGIA DE DENTES DECÍDUOS
}

\author{
Gabriela R. Pavan*, Lenita M. Lopes, Marinês N. dos S. Uchôa.
}

\section{Resumo}

O objetivo da pesquisa foi avaliar os efeitos da radiação sobre a microdureza, composição mineral e morfologia de dentes decíduos. Espécimes de dentes decíduos foram submetidos à radioterapia antes, após completar 1080, $2160 \mathrm{e}$ 3060 cGy. Os espécimes foram submetidos à microdureza de superfície, composição mineral e microscopia eletrônica de varredura. A radioterapia promoveu redução na dureza de superfície e alterações na composição mineral do esmalte e da dentina do dente decíduo. Além disso, houve alteração morfológica evidenciada pela microscopia de varredura.

Palavras-chave: Radioterapia. Dente Decíduo. Dureza. Análise Espectral Raman.

\section{Introdução}

Dependendo da área irradiada e da dose de irradiação, a radioterapia pode causar efeitos colaterais nas células que se encontram na direção do feixe de radiação. Apesar de o efeito da radioterapia nos dentes ser discutível no que tange ao risco de cárie, o qual envolve outros fatores, foi demonstrado que a radioterapia promove alterações nas estruturas dentárias dos dentes permanentes. Já os dentes decíduos apresentam composição química/morfológica diferente dos permanentes. Isso pode resultar em um comportamento diferente frente à exposição radioterápica. Sendo assim, o objetivo da pesquisa foi avaliar os efeitos da radiação sobre a microdureza, composição mineral e morfologia dos dentes decíduos.

Para isto, trinta espécimes de dentes decíduos foram submetidos à radioterapia em frações de 180 cGy. Previamente a radioterapia, (baseline) e após completar 1080, 2160 e 3060 cGy, os espécimes foram submetidos às análises de microdureza de superfície e composição mineral por espectroscopia RAMAN, na qual foram analizados os picos de fosfato $(9701 / \mathrm{cm})$, carbonato $(1070$ $1 / \mathrm{cm})$, e proteínas, essencialmente colágeno $(14401 / \mathrm{cm})$. A cada tempo experimental, dois espécimes foram guardados e submetidos posteriormente à microscopia eletrônica de varredura (MEV). Os resultados foram comparados entre os tempos experimentais pelo teste de Kruskal Wallis, seguido pelo Student-Newman-Keuls.

\section{Resultados e Discussão}

Pode-se observar uma redução da dureza de superfície do esmalte após 2160 cGy de radiação, quando comparado ao baseline. Para a dentina houve uma redução da dureza de superfície após 1080 cGy, e esta redução foi ainda maior após 2160 cGy. Porém, após completar 3060 cGy, a dureza de superfície não diferiu dos grupos anteriores, apenas do baseline.
Os resultados da composição mineral do esmalte demonstram que houve redução na concentração mineral do esmalte ao longo dos tempos experimentais. Houve uma redução estatisticamente significativa da concentração de fosfato após 2160 cGy e outra após 3060 cGy. Para Carbonato e colágeno, a concentração reduziu após 3060 cGy de radiação.

Para a dentina, foi observado aumento da concentração de fosfato e carbonato após 2160 cGy e uma redução após 3060 cGy de radiação. Foi observado também, um crescente aumento na concentração de colágeno após 1080 e 2160 cGy de radiação e uma redução após completar 3060 cGy de radiação.

Nas imagens obtidas por MEV, observou-se alterações morfológicas como aspecto de derretimento do esmalte e degradação da dentina peri-tubular resultando em obliteração progressiva dos túbulos ao longo das fases experimentais.

A redução da dureza de superfície, e redução da composição mineral do esmalte poderiam tornar o esmalte mais susceptível à desmineralização no processo cariogênico, e as alterações em dentina, principalmente após 3060 cGy, podem facilitar a progressão de cárie. Este estudo pode embasar futuros estudos sobre a susceptibilidade do dente decíduo irradiado à cárie.

\section{Conclusões}

A radioterapia provocou redução na dureza de superfície e alterações na composição mineral do esmalte e da dentina do dente decíduo. Além disso, houve alteração morfológica evidenciada por microscopia de varredura. 